\title{
Direct contact with perivascular tumor cells enhances integrin $\alpha v \beta 3$ signaling and migration of endothelial cells
}

\author{
Monica E. Burgett' ${ }^{1,6}$, Justin D. Lathia ${ }^{2}$, Patrick Roth ${ }^{7}$, Amy S. Nowacki ${ }^{4}$, Deni S. \\ Galileo ${ }^{10}$, Elena Pugacheva ${ }^{8}$, Ping Huang ${ }^{1}$, Amit Vasanji ${ }^{9}$, Meizhang Li ${ }^{2}$, Tatiana \\ Byzova $^{5}$, Tom Mikkelsen ${ }^{11}$, Shideng $\mathrm{Bao}^{3}$, Jeremy N. Rich ${ }^{3}$, Michael Weller7, \\ Candece L. Gladson ${ }^{1}$ \\ ${ }^{1}$ Department of Cancer Biology, Cleveland Clinic, Cleveland, OH, USA \\ ${ }^{2}$ Department of Cellular and Molecular Medicine, Cleveland Clinic, Cleveland, OH, USA \\ ${ }^{3}$ Department of Stem Cell Biology and Regenerative Medicine, Cleveland Clinic, Cleveland, OH, USA \\ ${ }^{4}$ Department of Quantitative Health Sciences, Cleveland Clinic, Cleveland, OH, USA \\ ${ }^{5}$ Department of Molecular Cardiology, Cleveland Clinic, Cleveland, OH, USA \\ ${ }^{6}$ School of Biomedical Sciences, Kent State University, Kent, $\mathrm{OH}$, USA \\ ${ }^{7}$ Department of Neurology, Laboratory of Molecular Neuro-Oncology, University Hospital, Zurich, Switzerland \\ ${ }^{8}$ Department of Biochemistry, West Virginia University, Morgantown, VA, USA \\ ${ }^{9}$ Image IQ, Inc., Cleveland, OH, USA \\ ${ }^{10}$ Department of Biological Sciences, University of Delaware and Helen F. Graham Cancer Center and Research Institute, \\ Christiana Care Health System, Newark, DE, USA \\ ${ }^{11}$ Department of Neurosurgery, Henry Ford Hospital, Detroit, MI, USA \\ Correspondence to: Candece L. Gladson, email: gladsoc@ccf.org \\ Keywords: endothelial cells, glioblastoma, angiogenesis, integrin $\alpha$ $\beta 3$, cancer stem cells \\ Received: September 24, $2015 \quad$ Accepted: May 13, $2016 \quad$ Published: May 30, 2016
}

\section{ABSTRACT}

The secretion of soluble pro-angiogenic factors by tumor cells and stromal cells in the perivascular niche promotes the aggressive angiogenesis that is typical of glioblastoma (GBM). Here, we show that angiogenesis also can be promoted by a direct interaction between brain tumor cells, including tumor cells with cancer stemlike properties (CSCs), and endothelial cells (ECs). As shown in vitro, this direct interaction is mediated by binding of integrin $\alpha v \beta 3$ expressed on ECs to the RGDpeptide in L1CAM expressed on CSCs. It promotes both EC network formation and enhances directed migration toward basic fibroblast growth factor. Activation of av $\beta 3$ and bone marrow tyrosine kinase on chromosome $X(B M X)$ is required for migration stimulated by direct binding but not for migration stimulated by soluble factors. RGDpeptide treatment of mice with established intracerebral GBM xenografts significantly reduced the percentage of Sox2-positive tumor cells and CSCs in close proximity to ECs, decreased integrin $\alpha \mathrm{V} \beta 3$ and BMX activation and p130CAS phosphorylation in the ECs, and reduced the vessel surface area. These results reveal a previously unrecognized aspect of the regulation of angiogenesis in GBM that can impact therapeutic anti-angiogenic targeting.

\section{INTRODUCTION}

A highly angiogenic phenotype is a distinctive feature of glioblastoma (GBM), and is thought to contribute to the aggressive growth, invasive phenotype and post-therapy recurrence of these tumors [1-3]. In GBM and other cancers, pro-angiogenic signaling molecules, including basic fibroblast growth factor (bFGF) and vascular endothelial growth factor A (VEGF-A), are secreted by stromal cells and tumor 
cells. These factors promote endothelial (EC) activation, survival, protease secretion, sprouting and migration [25]. Our understanding of how the angiogenic process is regulated is not complete, however; for example, regulation of VEGF-induced sprouting in ECs by metabolic pathways was shown recently [6].

The migration of ECs towards paracrine-acting pro-angiogenic factors is mediated by integrins in cooperation with growth factors/growth factor receptors [7, reviewed in [8-10]]. Cell surface-expressed integrins recognize and are activated by ligands typically localized in the extracellular environment. This activation, in turn, results in activation of cytoplasmic kinases, such as Src and focal adhesion kinase (FAK), as well as adaptor molecules, such as p130CAS, resulting in reorganization of the actin cytoskeleton and generation of the mechanical force needed to pull the cell forward [7-12]. Several integrins recognize an RGD-peptide in their ligands. Cell adhesion receptors other than integrins, including L1CAM, also can promote cell migration [reviewed in [13]]. L1CAM binds to RGDpeptide-binding integrins, including integrin $\alpha v \beta 3$ due to the presence of an RGD-peptide in its extracellular sixth Ig domain and this peptide appears to be necessary for the pro-migratory and pro-invasive effects of L1CAM in cancer cells [13-18].

In malignant tumors, a specialized perivascular microenvironment has been identified in which cancer stem-like cells (CSC) reside in very close proximity to ECs [19]. Use of integrin $\alpha 6$ as a marker of CSCs indicates that approximately $60 \%$ of integrin $\alpha 6$ positive cells reside within $5-\mu \mathrm{m}$ of blood vessels in GBM [20]. It has been suggested that ECs maintain the CSC population, promoting the survival of the CSCs through secreted soluble factors (e.g., nitric oxide) and laminin- $\alpha 2$ [20-23]. Conversely, the CSCs affect the ECs and promote angiogenesis through secretion of proangiogenic factors $[4,5]$. There is some evidence that CSCs may interact directly with ECs; medulloblastoma CSCs bind to ECs plated on Matrigel ${ }^{\circledR}$ and promote EC network formation [19] and melanoma cell contact with ECs in serum-containing media promotes expression of genes that regulate cancer cell migration and tumor progression [24]. Neither of these studies addressed the question of the mechanisms underlying the interactions or the identity of the cell type expressing the upregulated genes. Thus, the possibility that CSCs interact directly with ECs in the perivascular niche and affect EC behavior remains largely unexplored. We have examined direct interactions between primary brain ECs and CSCs derived from GBM or GBM cell lines and the subsequent signaling events using both in vitro approaches and an in vivo mouse model of GBM.

\section{RESULTS}

\section{Direct contact of ECs and CSCs involving cell- cell adhesion mediated by integrin $\alpha v \beta 3$ on ECs and L1CAM on CSCs}

Using a cell-cell adhesion assay, we found that the CSCs readily adhere/bind to a confluent monolayer of ECs plated on collagen and that 4-fold more CSCs adhered/ bound to ECs than to astrocytes (Figure 1A, SFigure 1A). Integrin $\alpha v \beta 3$, an RGD peptide-binding integrin that promotes $\mathrm{EC}$ adhesion, migration and survival [reviewed in $[8,9]]$, is upregulated on tumor-associated ECs in GBM biopsies [25]. The expression of the cell adhesion molecule L1CAM that contains an RGD-peptide is increased on CSCs from GBM [26]. Immunoblotting confirmed expression of the integrin $\beta 3$ subunit on ECs and expression of L1CAM on CSCs (Figure 1B). An antibody that blocks integrin binding to the RGD peptide in L1CAM $[14,27]$ reduced CSC adhesion to ECs (Figure 1A). Preincubation of ECs with a neutralizing antibody to integrin $\alpha v \beta 3$ or $\alpha v \beta 5$ significantly reduced CSC adhesion to ECs (43\% and $10 \%$, respectively), but pre-incubation with a neutralizing antibody to $\alpha 5 \beta 1$ did not (Figure $1 \mathrm{~A} \& 1 \mathrm{C}$ ). As anti-integrin $\alpha v \beta 3$ and anti-L1CAM in combination did not further inhibit CSC adhesion to ECs, integrin $\alpha \mathrm{v} \beta 3$ is most likely the major integrin involved in mediating this adhesion (Figure 1A). A cyclic-RGD-peptide significantly inhibited CSC adhesion to ECs in a concentration-dependent manner whereas a control RAD-peptide did not (Figure 1D). Downregulation of either the integrin $\beta 3$ subunit on ECs or L1CAM on CSCs using pooled siRNA significantly inhibited CSC adhesion to ECs (Figure 1E). Similarly, downregulation of either the integrin $\beta 3$ subunit on ECs or L1CAM on CSCs using two different single-target siRNAs for integrin $\beta 3$ and two different single target-siRNAs for L1CAM significantly inhibited CSC adhesion to ECs (Figure 1F\&1G). Moreover, overexpression of L1CAM in U-118 MG GBM cells (L1LE) [28] promoted the binding of GBM cells to ECs as compared to U-118 MG cells expressing the vector control (Figure $1 \mathrm{H}$ ) and the expression of L1CAM on the 08387 CSCs promoted increased binding of CSCs to ECs as compared to the paired 08387 non-stem tumor cells (NSTCs) (SFigure 1B).

\section{CSCs from GBM promote network formation by brain ECs, activation of integrin $\alpha v \beta 3$ and phenotypic changes in ECs}

On co-seeding primary brain ECs with CSCs on Matrigel $^{\circledR}$, an interaction between ECs and CSCs could be seen at $2 \mathrm{~h}$ (SFigure 1C). The number of EC segments/ branches (network formation) was higher on co-seeding 
of CSCs with ECs than when ECs were seeded in CSCconditioned media (CM) (Figure 1I). This significantly higher number of segments/branches on co-seeding of CSCs with ECs than when ECs were seeded in CM
(ECs+CSCs) was observed when the ECs were pre-seeded at 2,4 , or $18 \mathrm{~h}$ prior to the addition of CM (ECs+CSCs) or CSCs (Figure 1J).Thus, in subsequent experiments we differentiated the effects of direct contact to those of

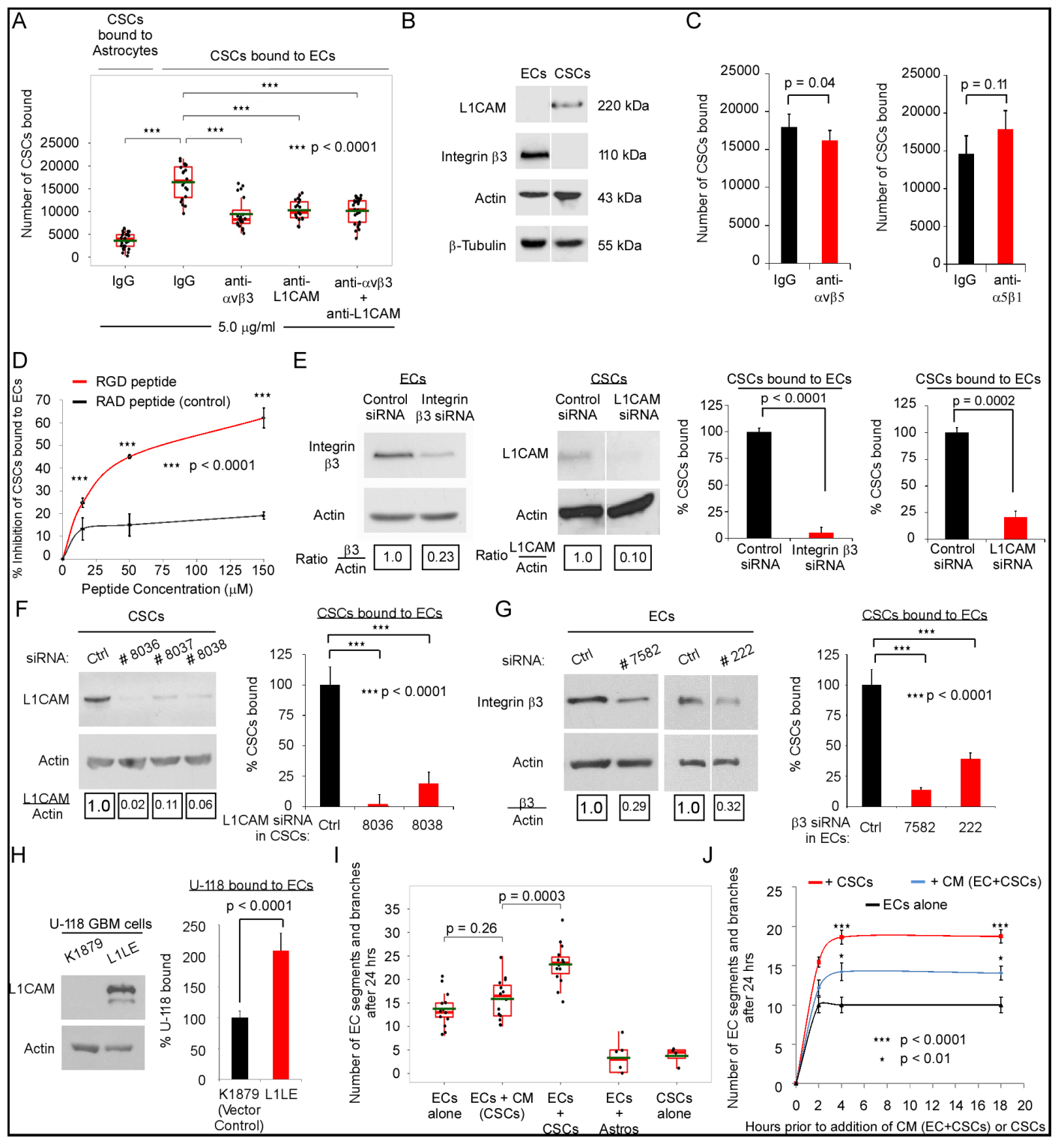

Figure 1: Integrin $\alpha v \beta 3$ on ECs and L1CAM on CSCs mediate the direct contact of ECs and CSCs. A-H. CSC adhesion measured by plating of GFP-CSCs-(08387) $\left(3 \times 10^{4}\right)$ over unlabeled-ECs or astrocytes $\left(5 \times 10^{4} /\right.$ well $)$ that had been seeded in serum-free adhesion assay buffer on plates coated with $10 \mu \mathrm{g} / \mathrm{mL}$ collagen. The GFP-CSCs-(08387) were incubated with the ECs or astrocytes (30 $\mathrm{min}$ ), washed $3 \mathrm{X}$ with PBS and CSC adhesion to the EC or astrocyte monolayer measured by detection of GFP-CSC fluorescence using a fluorometer (485nm absorption, $535 \mathrm{~nm}$ emission) (replicates of five). (A-D) In some experiments, after overnight attachment, the seeded ECs or astrocytes were incubated with blocking antibody (A, C) or RGD peptide (D) or the corresponding controls for 30 min and the CSCs were incubated with blocking antibody (A, C) or RGD peptide (D) or the corresponding controls (30 min) prior to plating the CSCs over the EC or astrocyte monolayer. Expression of integrin $\beta 3$ and L1CAM on adherent ECs and CSCs was determined by immunoblotting (B). (E-H) In some experiments, the ECs or CSCs were pretreated with pooled siRNA to $\beta 3$ or L1CAM for 48h (E); or single target siRNA to L1CAM for $72 \mathrm{~h}(\mathrm{~F})$ or $\beta 3$ for $72 \mathrm{~h}(\mathrm{G})$; or adhesion of L1CAM overexpressing (L1LE) cells and U-118 MG cell vector control (K1879) to an EC monolayer was measured (H). I-J. Network/branch formation quantified as the number of segments/branches at $24 \mathrm{~h}$ after seeding of red-fluorescent ECs $(20,000)$ alone or mixed with GFP-CSCs $(20,000)$ or with astrocytes $(20,000)$ onto Matrigel ${ }^{\circledR}$ in complete NBM (I) or after seeding onto Matrigel ${ }^{\circledR}$ in complete NBM 2, 4, or $18 \mathrm{~h}$ prior to the addition of CM (ECs+CSCs) or CSCs (J). Statistics: A, C, E-I, two-sided exact Wilcoxon rank-sum tests; D, two-way ANOVA; and J, repeated measure ANOVA. Graphs: A \& I, Box and Whisker plots, $\mathrm{C}, \mathrm{E}-\mathrm{H}$, data plotted as bar graphs, mean \pm SEM. 
soluble factors by comparing the effects of co-seeding to the effects of CM.

For the subsequent experiments, we used laminin as the substrate as CSCs from GBM retain their stem cell phenotype when plated on laminin in neural basal media (NBM) [29] and integrin $\alpha 6 \beta 1$ mediates brain EC attachment to laminin [30].

To determine whether the direct contact activates ECs, we analyzed mRNA levels of two markers of EC activation using qRT-PCR. The results indicated significantly higher E-selectin and VCAM-1 mRNA levels (9-fold and 34-fold, respectively) in ECs that were co-seeded with CSCs than in ECs seeded in CM obtained from co-seeded ECs and CSCs (CM/EC+CSC) at $3 \mathrm{~h}$, indicating that $\mathrm{EC}$ activation was not induced by a secreted factor at this time point (Figure 2A).

Addition of recombinant L1CAM to ECs seeded alone resulted in activation of integrin $\alpha v \beta 3$, as assessed by staining for phospho- $\beta 3$ (pY759) [31, 32], confirming that integrin $\alpha v \beta 3$ can be activated upon binding L1CAM (Figure 2B). The growth factor bFGF is upregulated in GBM; thus, to determine whether integrin $\alpha v \beta 3$ on ECs is activated on binding L1CAM on CSCs, we co-seeded ECs and CSCs on laminin in the presence of bFGF ( $3 \mathrm{~h})$ using Sox 2 as a positive control for CSCs [33]. A significant increase in integrin $\beta 3$ phosphorylation was observed when ECs were co-seeded with CSCs (Figure 2B).

Co-seeding of ECs with CSCs resulted in a phenotypic change in the ECs (Figure 2C). The number of ECs with stress fibers was significantly lower and the number with cortical actin was significantly higher as compared to ECs seeded in $\mathrm{CM} / \mathrm{EC}+\mathrm{CSC}$ (Figure $2 \mathrm{C} \& 2 \mathrm{D})$. This suggested induction of a pro-migratory phenotype in the ECs on co-seeding with CSCs. As the phosphorylation of early downstream signaling effectors FAK and p130CAS is dynamic and depends on an organized actin cytoskeleton [reviewed in [8-10]], we quantitated the intensity of p130CAS phosphorylation (pY234) in confocal stacks of ECs. In ECs co-seeded with CSCs, phospho-p130CAS-(pY234) was nearly 3 -fold higher than in ECs seeded in $\mathrm{CM} / \mathrm{EC}+\mathrm{CSC}$ (Figure 2E\&2F); however, there was no significant difference in total p130CAS in ECs co-seeded with CSCs versus ECs seeded alone in $\mathrm{CM} / \mathrm{EC}+\mathrm{CSC}$, based on cell harvest with Accutase, sorting for CD31, cell lysis and blotting for p130CAS (Figure 2F). FAK activity (pY397) was similarly increased in the ECs co-seeded with CSCs, as compared to ECs seeded in $\mathrm{CM} / \mathrm{EC}+\mathrm{CSC}$ (data not shown). Double-labeling for phosphorylated p130CAS and actin (Alexa-594-Phalloidin) followed by confocal microscopy showed focal co-localization at the membrane in ECs co-seeded with CSCs (Figure 3A). The downstream effectors ERK and JNK also can promote cell migration [34]. The activation of ERK and JNK was significantly higher in ECs co-seeded with CSCs from four different GBM tumors as compared to ECs seeded in CM/EC+CSC, and this increase was blocked by addition of RGD peptide (Figure 3B-3D; SFigure 2A). Collectively, these results suggest that the direct interaction between CSCs and ECs might represent a pro-angiogenic behavior of ECs as indicated by network formation and a transition in the ECs from a quiescent phenotype to an activated, migratory phenotype.

\section{CSCs increase the motility of ECs through direct contact as well as secreted factors}

We investigated the effect of CSCs on EC migration using a 2D cell motility assay in which ECs and CSCs were seeded in NBM on laminin on either side of a $500-\mu \mathrm{m}$ gap, and migration assessed over $24 \mathrm{~h}$ by liveimaging (Figure 4A). EC migration was almost completely inhibited by a neutralizing anti-integrin $\alpha 6$ antibody (Figure 4B). As compared to positioning of CSCs or ECs on both sides of the gap, the positioning of CSCs opposite ECs (on either side of the gap) significantly increased EC and CSC migration into the gap (10- and 14-fold, respectively; Figure 4C; SFigure 2B). Moreover, by $24 \mathrm{~h}$ the cells had filled the gap, whereas at this time point only $35 \%$ of the gap was filled when either CSCs or ECs were plated on both sides.

Live video imaging showed that contact between the ECs and CSCs first occurred after $7 \mathrm{~h}$ in this assay (Figure $4 \mathrm{H})$; thus, the effects of potential CSC-secreted factors in the absence of direct contact could be assessed during the first $7 \mathrm{~h}$. On tracing the paths of $30 \mathrm{ECs}$, we found that in the absence of CSCs (-CSCs), the ECs migrated randomly whereas when CSCs were present the majority of ECs displayed a preferential migration in the direction of the CSCs (negative X axis) (Figure 4D; SFigure 2C). During the first $7 \mathrm{~h}$, there was no significant difference in the velocity of the ECs when plated opposite CSCs or ECs (Figure 4F). Thus, potentially, CSC-secreted factors promote the directional motility of ECs but do not alter the velocity.

We then assessed the effects of direct contact of CSCs with ECs on EC migration by tracing trajectories during the 7-24 h time frame. We compared the trajectories of 30 ECs that had been observed to make contact with CSCs during the 7-24 h time frame with the trajectories of 30 ECs that never contacted CSCs but were plated opposite of CSCs, over the same time frame. We found that the ECs that had been observed to contact CSCs exhibited a significantly greater displacement and velocity (21.3 $\mu \mathrm{m}$ and $0.3 \mu \mathrm{m} / \mathrm{min}$, respectively), and exhibited directional migration, compared to the ECs that had never contacted CSCs $(3.4 \mu \mathrm{m}$ and $0.23 \mu \mathrm{m} / \mathrm{min}$, respectively) (Figure 4E\&4G; SFigure 2D). ECs that were seeded in the absence of CSCs continued to display random migration (SFigure 2E).

To assess the effect of EC-CSC contact on EC migration towards a chemo-attractant, we used a 
Transwell ${ }^{\circledR}$ assay with laminin-coated $3-\mu \mathrm{m}$ pore filters to mimic the tight spaces in the brain extracellular matrix [35] (Figure 5A). Red-fluorescent-ECs were mixed, coseeded with GFP-CSCs in the upper chamber and allowed to migrate for $6 \mathrm{~h}$ towards bFGF in NBM in the bottom chamber. Co-seeding of ECs with CSCs in the top chamber significantly increased EC migration as compared to migration of ECs seeded alone in the top chamber (Figure $5 \mathrm{~B})$. The increase in EC migration when co-seeded with CSCs was not replicated by seeding ECs in $\mathrm{CM} / \mathrm{EC}+\mathrm{CSC}$, indicating the increase in EC migration was not due to a secreted factor(s) (Figure 5C).

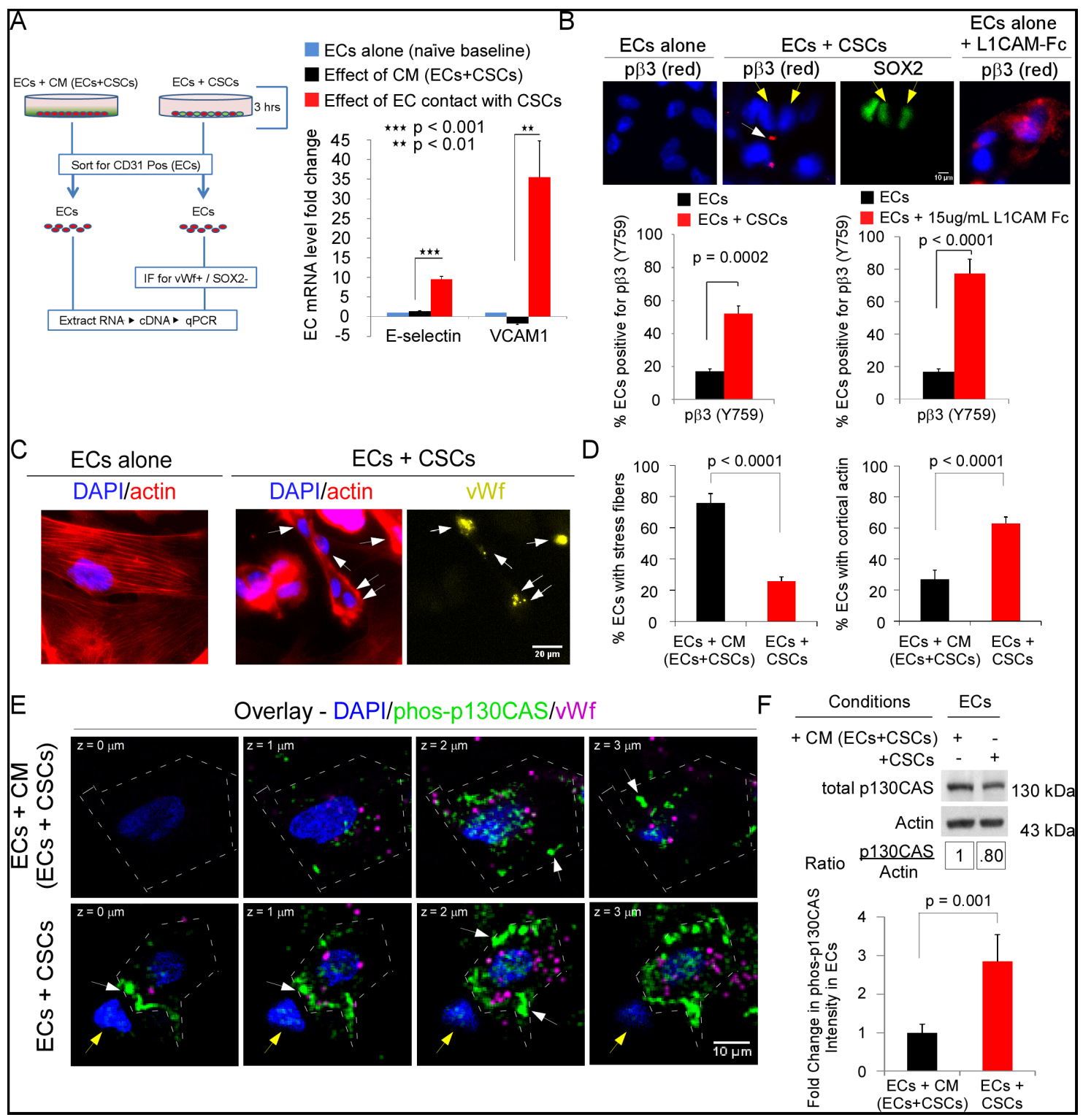

Figure 2: The direct interaction of ECs and CSCs activates ECs and promotes activation of integrin $\alpha \mathrm{\beta} 3$ and p130CAS in ECs. A. mRNA levels of genes marking EC activation were measured by qRT-PCR analysis of ECs seeded onto laminin in CM/ $\mathrm{EC}+\mathrm{CSC}$ (in growth-factor-free NBM) or mixed directly with CSCs-(08387) (growth-factor-free $\mathrm{NBM}$ ) for $3 \mathrm{~h}\left(37^{\circ} \mathrm{C}, 5 \% \mathrm{CO}_{2}\right)$. $\mathrm{ECs}$ were then isolated by sorting for CD31. mRNA levels of genes after normalization to GAPDH are shown. B-F. Immunofluorescent analysis of markers of activation and signaling in ECs. ECs in CM/EC+CSC (growth factor-free NBM $+10 \mathrm{ng} / \mathrm{ml}$ bFGF) or mixed directly with CSCs (growth factor-free NBM + bFGF) were seeded onto laminin $(3 \mathrm{~h})$. Representative photomicrographs and quantification of phospho- $\beta 3$ (Y759), a marker of integrin $\alpha v \beta 3$ activation; white arrows denote phospho- $\beta 3$ and yellow arrows denote CSCs (B); phalloidin-Alexa-594 (binds actin) and vWf (Alexa-647-yellow); arrows denote ECs with cortical actin or vWf expression (C-D); phosphorylated p130CAS (phos-p130CAS Y234; Alexa-488, green) and vWf (magenta); white arrows, green phos-p130CAS; and yellow arrows, CSCs (E). The intensity of green signal calculated using FIJI (ImageJ) based on the sum of the mean gray level (intensity) output of all pixels of the area within the enclosed cell traced along its outer edge, for each confocal section taken at $0.5 \mu \mathrm{m}$ steps comprising the Z-stack. Signal intensity was normalized by dividing the sum of the mean gray level by the area of the cell. (F). Statistics: A, B, D and F, two-sided exact Wilcoxon rank-sum tests; data plotted as mean \pm SEM. 
Src phosphorylates the substrate domain of p130CAS, which is necessary for p130CAS activation [reviewed in [8-10]]. Preincubation of ECs with the Src inhibitor 4-amino-5-(4-chlorophenyl)-7-(dimethylethyl) pyrazolo[3,4- $\alpha$ pyrimidine (PP2) for $20 \mathrm{~min}$ followed by washing and seeding significantly inhibited EC migration towards bFGF whether the treated ECs were co-seeded with CSCs or seeded alone (Figure 5B). Downregulation of $\beta 3$ in ECs resulted in a significant decrease in migration of ECs co-seeded with CSCs (Figure 5D), but had no significant effect on the migration of ECs that were seeded alone (Figure 5D). This was consistent with our observation that integrin $\alpha v \beta 3$ is not mediating adhesion or migration of ECs on laminin. Downregulation of L1CAM on CSCs also resulted in a significant reduction in migration of ECs co-seeded with CSCs (Figure 5E). Collectively, these data suggest that the interaction of CSCs with ECs activates signaling effectors in ECs thereby promoting migration towards bFGF that is not mediated by binding of integrin $\alpha v \beta 3$ to the laminin substrate.

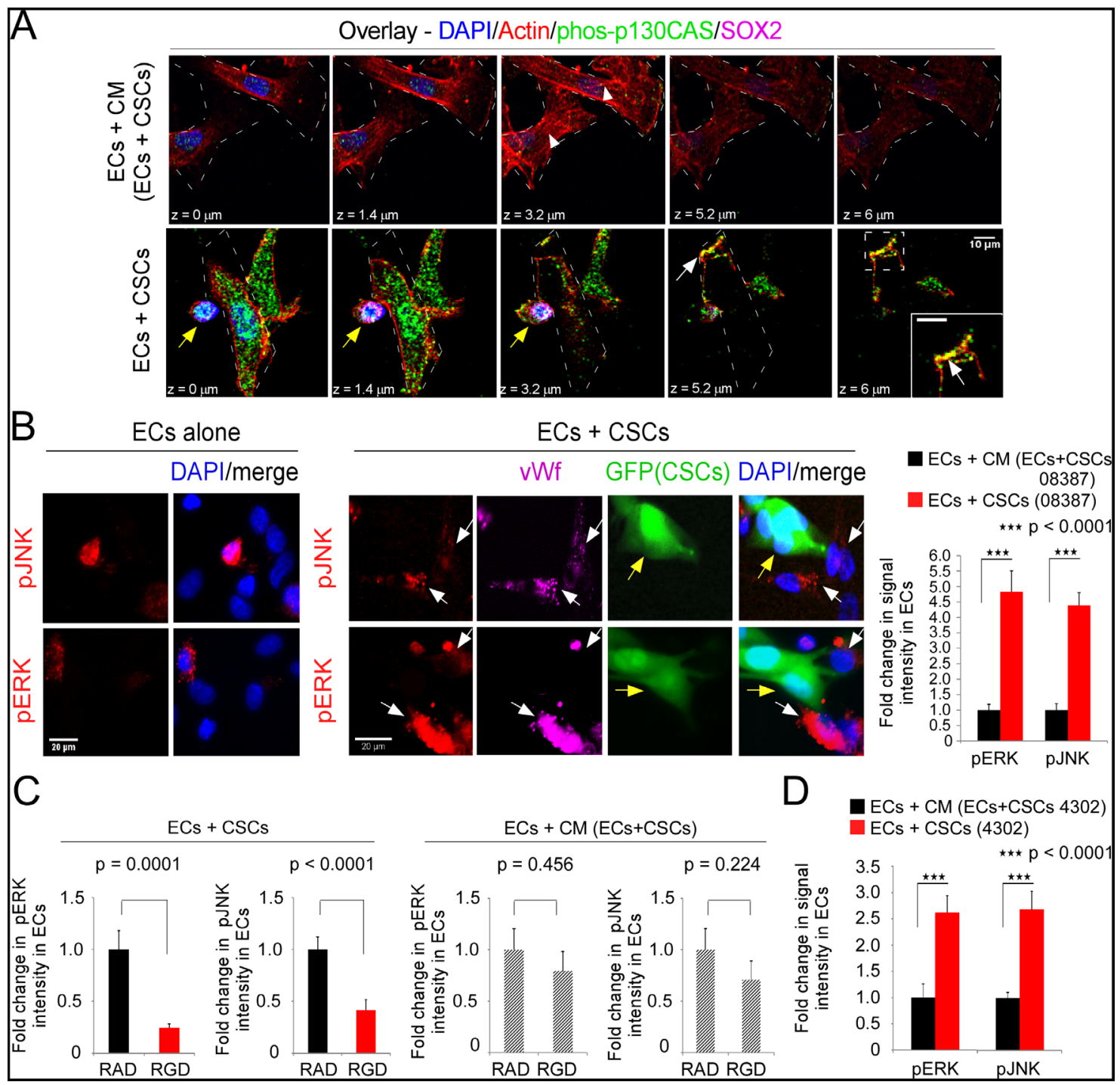

Figure 3: The direct interaction of ECs and CSCs activates ERK and JNK in ECs in an RGD-peptide-dependent manner. ECs were seeded alone or with CSCs as in Figure 2B and markers detected by immunofluorecent labeling followed by confocal microscopy. A. Phosphorylated p130CAS (Y234) (Alexa-488, green) and actin (Alexa-594-Phalloidin, red). Sections comprising the Z-stack shown; white arrowheads-actin stress fibers; white arrows-co-localization (yellow) of phos-p130CAS and actin at membrane; and yellow arrows-CSCs. B. Phospho-ERK or phospho-JNK (Alexa-594, red) and vWf (Alexa-647, magenta). White arrows denote vWfpositive ECs expressing pERK or pJNK; and yellow arrows denote GFP-CSCs-(08387). C. RGD- or RAD-peptide (50 $\mu \mathrm{M})$ were incubated with cells during seeding. D. ECs co-seeded with a second CSC isolate (4302) or in CM/EC+CSC; fluorescent intensity analyzed in 50 ECs and graphed as the fold-change. Statistics: B and C, two-sided student t-tests and D, two-sided Wilcoxon rank-sum test; B-D, Fold change in $\mathrm{pERK}$ or $\mathrm{pJNK}$ graphed as the mean $\pm \mathrm{SEM}$. 
Bone marrow tyrosine kinase on chromosome $\mathrm{X}(\mathrm{BMX})$ as well as FAK and p130CAS are required for enhanced migration of ECs towards bFGF when co-seeded with CSCs

To determine whether p130CAS was necessary for the enhanced migration of ECs when co-seeded with CSCs, we downregulated p130CAS in the ECs with two different single target siRNAs or pooled p130CAS siRNA (Figure 5F, SFigure 3A). This resulted in a significant inhibition of EC migration towards bFGF when co-seeded with $\mathrm{CSCs}$ or when seeded in $\mathrm{CM} /$
$\mathrm{EC}+\mathrm{CSC}$ (Figure 5G, SFig 3B). Both FAK and BMX can phosphorylate p130CAS, although at different sites, and contribute to p130CAS activation [8-10,36]. When FAK was downregulated in the ECs, we found a significant inhibition of EC migration whether the ECs were coseeded with CSCs or seeded in $\mathrm{CM} / \mathrm{EC}+\mathrm{CSC}$ (Figure $5 \mathrm{~F} \& 5 \mathrm{H})$. In contrast, when BMX was downregulated in the ECs we found a significant inhibition of EC migration when the ECs were co-seeded with CSCs, but not when they were seeded alone in $\mathrm{CM} / \mathrm{EC}+\mathrm{CSC}$ (Figure $5 \mathrm{~F} \& 5 \mathrm{H}$ ). Supporting these findings, the use of a FAK or a BMX inhibitor $(1 \mu \mathrm{M})$ showed highly similar effects on EC

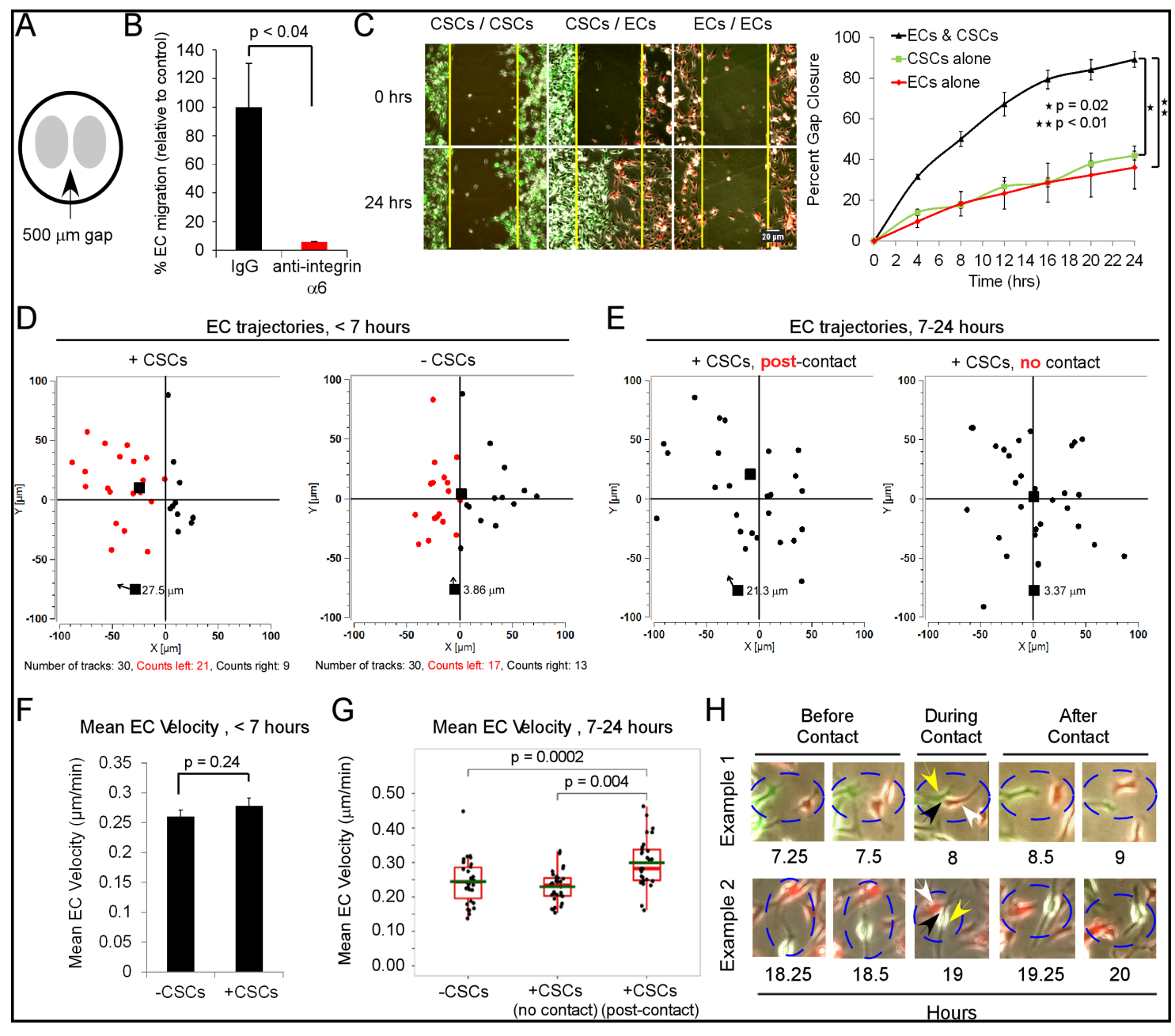

Figure 4: CSCs increase the directional 2D motility of ECs through both secreted factors and direct contact. A. EC migration is mediated by an $\alpha 6$ integrin. Cell culture inserts were coated with $20 \mu \mathrm{g} / \mathrm{mL}$ laminin, and red-fluorescent-ECs $(30,000$, EGM media) were plated on one side of the insert, and GFP-CSCs-(08387) $(30,000$, complete NBM) on the other side. At $18 \mathrm{~h}$, all media were replaced with complete NBM; the insert removed, and live-imaging performed q $15 \min \left(24 \mathrm{~h}, 37^{\circ} \mathrm{C}, 5 \% \mathrm{CO}_{2}\right)$. Migration was measured by counting each fluorophore in an automated fashion (customized software). B. In certain experiments, blocking anti-integrin $\alpha 6$ antibody or IgG as a control $(5 \mu \mathrm{g} / \mathrm{ml})$ was included in the complete NBM and nearly completely inhibited EC migration towards CSCs. C. Plot of gap closure. D. Paths of 30 ECs were manually traced in the first $7 \mathrm{~h}$ before EC-CSC contact and E. between $7-24 \mathrm{~h}$ when EC-CSC contact occurs using Manual Tracker (Image J). The final destination of each EC denoted on the graph, mean overall displacement-Euclidean distance (all $30 \mathrm{ECs}$ ) shown with the arrow. F. Mean EC velocity (displacement/time- $\mu \mathrm{m} / \mathrm{min}$ ) graphed as a bar graph of the mean $\pm \mathrm{SEM}$ or G. as Box and Whisker plots. H. Examples of ECs contacting CSCs in the gap area at various time points after $7 \mathrm{~h}$; white arrows-ECs, yellow arrows-CSCs, and black arrowhead-point of EC-CSC contact. Statistics: C, F, and G, two-sided exact Wilcoxon rank-sum tests. 
migration as compared to downregulation of FAK or BMX expression, respectively (Figure 5I). This indicates a differential requirement for BMX for the increased chemotactic migration of ECs when they are co-seeded with CSCs.
We therefore determined whether BMX was necessary for p130CAS activation in ECs co-seeded with CSCs, by downregulating BMX in ECs that were then co-seeded with CSCs on laminin in NBM with bFGF (3 h). The downregulation of BMX significantly inhibited

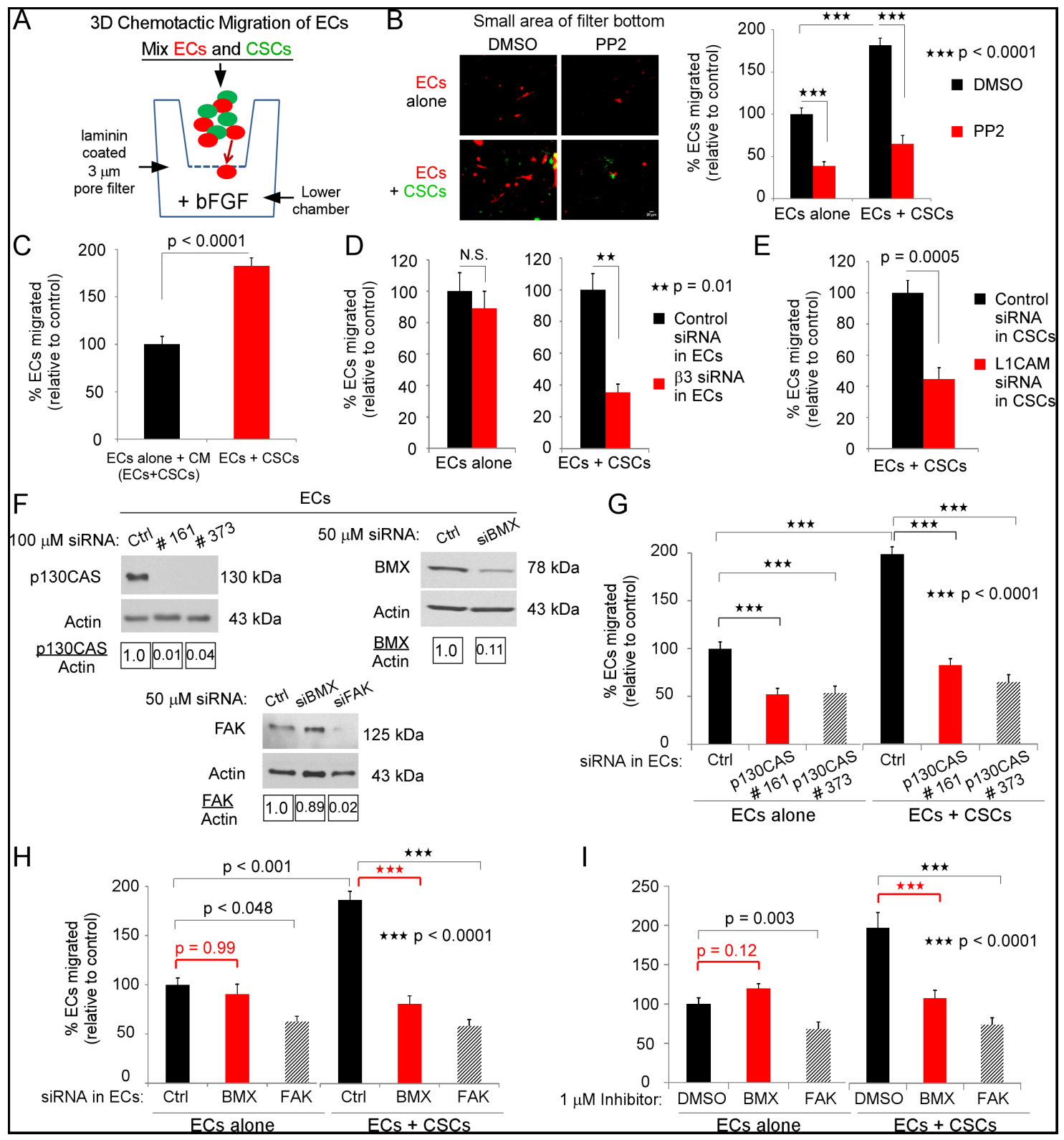

Figure 5: The direct interaction of ECs and CSCs promotes EC migration towards bFGF. A. Diagrammatic representation of experimental design. Filters (3- $\mu \mathrm{m}$ pore) were coated on both sides with $20 \mu \mathrm{g} / \mathrm{mL}$ laminin. Red-fluorescent-ECs $\left(3 \times 10^{4}\right)$ were seeded alone or mixed with GFP-CSCs-(08387) $\left(3 \times 10^{4}\right)$ and co-seeded in growth factor-free NBM with $1 \%$ BSA on top of the filter. Growth factor-free NBM with $10 \mathrm{ng} / \mathrm{ml} \mathrm{bFGF}$ was placed in the bottom chamber, and the cells allowed to migrate $\left(37^{\circ} \mathrm{C}, 5 \% \mathrm{CO}_{2}\right)$. At $6 \mathrm{~h}$, cells were removed from the upper filter surface and cells on the lower filter surface were washed, fixed, photographed and quantified. B. The Src inhibitor PP2 $(1 \mu \mathrm{M})$ was incubated with ECs $(20 \mathrm{~min})$, followed by washing, and EC seeding alone or co-seeding with CSCs. C. ECs were seeded in $\mathrm{CM} / \mathrm{EC}+\mathrm{CSC}$ (described in Figure $2 \mathrm{~B}$ ), or co-seeded with CSCs. D, E. ECs were treated with integrin $\beta 3$ specific siRNA, L1CAM specific siRNA or with control siRNA for $48 \mathrm{~h}$, washed and seeded alone or with GFP-CSCs. F-H. Downregulation by

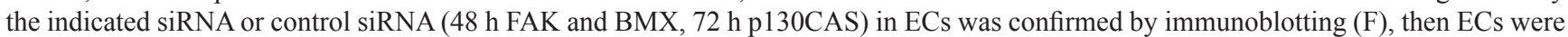
treated with p130CAS, FAK or BMX specific siRNA or with control siRNA, washed and seeded alone or with GFP-CSCs. I. ECs were treated with $1 \mu \mathrm{M}$ of the FAK or BMX inhibitor or DMSO (control), washed and seeded alone or with GFP-CSCs. Statistics: B-E, G-I, twosided exact Wilcoxon rank-sum tests, and data graphed as the mean \pm SEM. 
p130CAS phosphorylation in ECs co-seeded with CSCs but had no effect on p130CAS phosphorylation in ECs seeded alone in $\mathrm{CM} / \mathrm{EC}+\mathrm{CSC}$ (Figure 6A\&6B). To determine whether BMX was activated in ECs on coseeding with CSCs, phospho-BMX was detected by immunofluorescence and fluorescent intensity quantitated as described for phospho-p130CAS. We found a significant increase ( $\sim 3$-fold) in phospho-BMX in ECs co-seeded with CSCs as compared to ECs seeded alone in $\mathrm{CM} / \mathrm{EC}+\mathrm{CSC}$ (Figure $6 \mathrm{C} \& 6 \mathrm{~F}$ ) although there was no significant difference in total BMX in ECs in the two conditions after Accutase harvest, CD31 sorting, lysis and blotting for BMX (Figure 6E). To further determine whether the increase in phospho-BMX was dependent on integrin $\alpha v \beta 3$ in the ECs co-seeded with CSCs, we downregulated the $\beta 3$ subunit in ECs. There was a significant inhibition of BMX phosphorylation in the ECs in which the $\beta 3$ subunit was downregulated when they were co-seeded with CSCs, but the BMX phosphorylation in these ECs was unaffected when they were seeded alone in $\mathrm{CM} / \mathrm{EC}+\mathrm{CSC}$ (Figure 6C, 6D\&6F). Taken together, these data indicate that $\mathrm{BMX}$ is necessary for the increased p130CAS activation and EC migration towards bFGF in ECs co-seeded with CSCs on laminin, but is not necessary for p130CAS activation and EC migration when ECs are seeded alone.

\section{RGD-peptide treatment reduces the proximity of Sox2-positive tumor cells to ECs and decreases phosphorylation of BMX and p130CAS in ECs in a xenograft model of GBM}

Others have reported that cyclic-RGD-peptide (Cilengitide) treatment prolongs survival of scid mice bearing intracerebral GBM tumors, and of nude rats bearing intracerebral GBM tumors when administered with radiation [37, 38]. As we had found that an RGDpeptide blocks the interaction of integrin $\alpha v \beta 3$ on ECs with L1CAM on CSCs, we examined the effects of administration of the cyclic-RGD-peptide in an established orthotopic mouse model of GBM on the distance of Sox2-positive tumor cells from ECs and integrin $\alpha v \beta 3$ mediated signaling in the ECs. LN-308 GBM cells were utilized as they express L1CAM when propagated as neurospheres in NBM (Figure 7A), bind to ECs in the cell-cell adhesion assay in an L1CAM-dependent manner (Figure 7B), and promote EC migration towards bFGF in an L1CAM-dependent manner (Figure 7C\&7D). LN-308 cells were injected into the nude mouse brain and at day 55 administration of cyclic RGD-peptide was initiated, followed by euthanasia and brain harvest on day 60 . We found a significant increase in the mean distance of Sox2positive cells from ECs (Figure 7E\&7F), and a significant decrease in the number of Sox2-positive cells within 25$\mu \mathrm{m}$ of blood vessels (Figure 7F\&7G). Also, we found significant decreases in the percent of ECs expressing $\mathrm{p} \beta 3$-(Y759), in the intensity of phospho-BMX (BMX activation) and phospho-p130CAS in ECs, and in vessel surface area in the tumors of RGD-peptide treated mice as compared to controls (Figure 7F, 7H-7K). Phospho-BMX staining of ECs in the xenograft tumors was detected in a population of vessels, consistent with BMX expression in vessels of arterial origin [39, 40]. These data suggest that ECs interact with tumor cells in the perivascular niche through an RGD-peptide-binding integrin and that this interaction promotes BMX and p130CAS activation, thereby enhancing angiogenesis.

\section{DISCUSSION}

Here, we describe for the first time a direct interaction of ECs with CSCs from GBM that is mediated through binding of integrin $\alpha v \beta 3$ on ECs to the RGDpeptide in the extracellular domain of L1CAM on CSCs. This activates integrin $\alpha v \beta 3$ on ECs and, in the presence of bFGF, results in significantly increased activation of BMX, FAK and p130CAS, increased activation of the downstream effectors ERK and JNK, and marked changes in the phenotype of the ECs. Importantly, this level of upstream and downstream effector activation was not achieved by EC seeding in $\mathrm{CM} / \mathrm{EC}+\mathrm{CSC}$ with bFGF, indicating that it cannot be attributed to a secreted factor(s). Furthermore, the increase in ERK and JNK activation was RGD-peptide-dependent suggesting a requirement for the direct interaction of ECs with CSCs rather than an effect due to integrin $\alpha 6$-mediated adhesion to laminin (which is RGD-peptide-independent) [reviewed in $[8,9]]$. Minimal p130CAS activation was detected in CSCs, suggesting activation of another p130CAS family member, such as NEDD9(HEF1) [12, 41]. In ECs co-seeded with CSCs, we found that integrin $\alpha v \beta 3$ is necessary for BMX activation and that BMX is necessary for p130CAS activation whereas in ECs seeded in CM/ $\mathrm{EC}+\mathrm{CSC}, \alpha v \beta 3$ is not necessary for BMX activation and BMX is not necessary for p130CAS activation. BMX, a cytoplasmic non-receptor tyrosine kinase, can activate signaling pathways that promote migration and angiogenesis as well as other signaling pathways $[39,40$, 42-46]; thus, the increased BMX activity downstream of activated integrin $\alpha v \beta 3$ in the ECs co-seeded with CSCs could serve to amplify and diversify signaling.

The alterations in the actin cytoskeleton that occurred in ECs that contact CSCs suggest a pro-migratory phenotype, and co-seeding ECs with CSCs on laminin significantly increased EC migration towards bFGF as compared to that observed when the ECs were seeded on laminin in $\mathrm{CM} / \mathrm{EC}+\mathrm{CSC}$. This increased migration was dependent on integrin $\alpha v \beta 3$ on ECs and L1CAM on CSCs, supporting our hypothesis that the direct cell-cell contact promotes EC migration towards bFGF. The possibility that the migration was mediated by integrin $\alpha \mathrm{v} \beta 3$ binding to the laminin substrate was ruled out by the failure of 
downregulation of $\beta 3$ to significantly affect migration of the ECs seeded alone on laminin.

The current studies focus specifically on the effects of EC-CSC contact mediated by integrin $\alpha v \beta 3$ on EC signaling and migration. To characterize this response, we focused on the 7-24 h time frame when cell-cell contact and directed migration were observed. We found distinct differences between the signals associated with migration

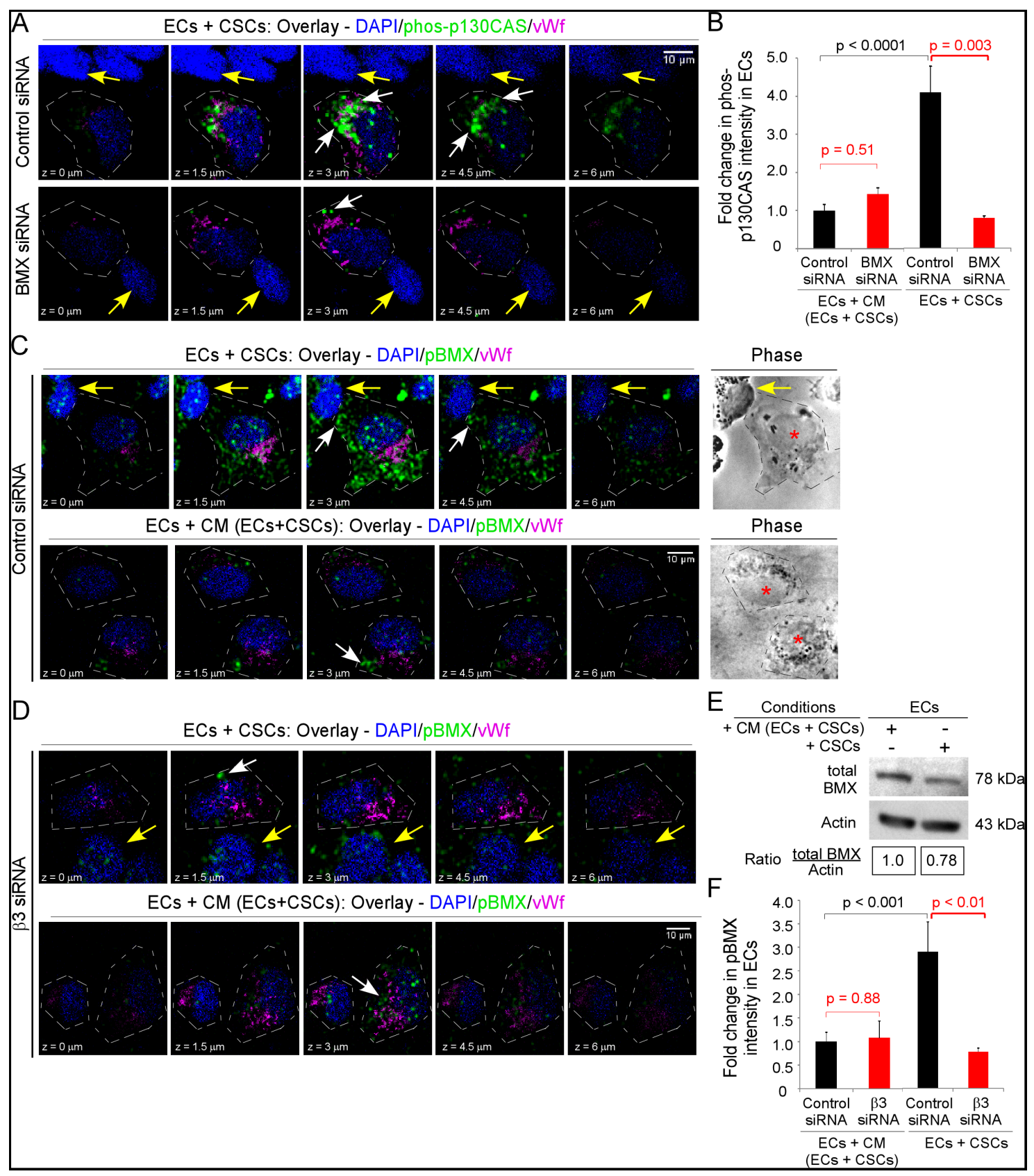

Figure 6: Integrin $\alpha v \beta 3$ is necessary for BMX activation and BMX is necessary for p130CAS activation in ECs contacting CSCs. ECs were seeded alone or with CSCs-(08387) as in Figure 2B. A-B. ECs were treated with BMX siRNA or control siRNA (48 h), followed by seeding as above and immunofluorescence for phos-p130CAS (Y234) (Alexa-488, green) and vWf (Alexa-647, magenta, marker of ECs). Confocal sections (0.5- $\mu \mathrm{m}$ apart) comprising the Z-stack are shown. White arrows denote phos-p130CAS and yellow arrows denote CSCs (vWf-negative) (A). The intensity of phos-p130CAS was determined in 15 representative cells as in Figure $2 \mathrm{E} \& 2 \mathrm{~F}$ and graphed as the fold-change. (B). C-F. ECs were treated with control siRNA (C) or integrin $\beta 3$ siRNA (D) for $48 \mathrm{~h}$, followed by seeding as above and immunofluorescence detection of phospho-BMX (pBMX) (Alexa-488 green) and vWf (Alexa-647, magenta, EC marker). Confocal sections (0.5- $\mu \mathrm{m}$ apart) comprising the Z-stack are shown. White arrows denote pBMX, yellow arrows denote CSCs (vWf-negative) and red asterisks denote ECs in phase contrast images (C,D). The intensity for pBMX was determined in 15 representative cells as in Figure 2E\&2F and graphed as the fold-change. (F). Cells were harvested with Accutase, sorted for CD31, detergent lysed and immunoblotted as indicated (E). Statistics: B and F, two-sided exact Wilcoxon rank-sum tests. 


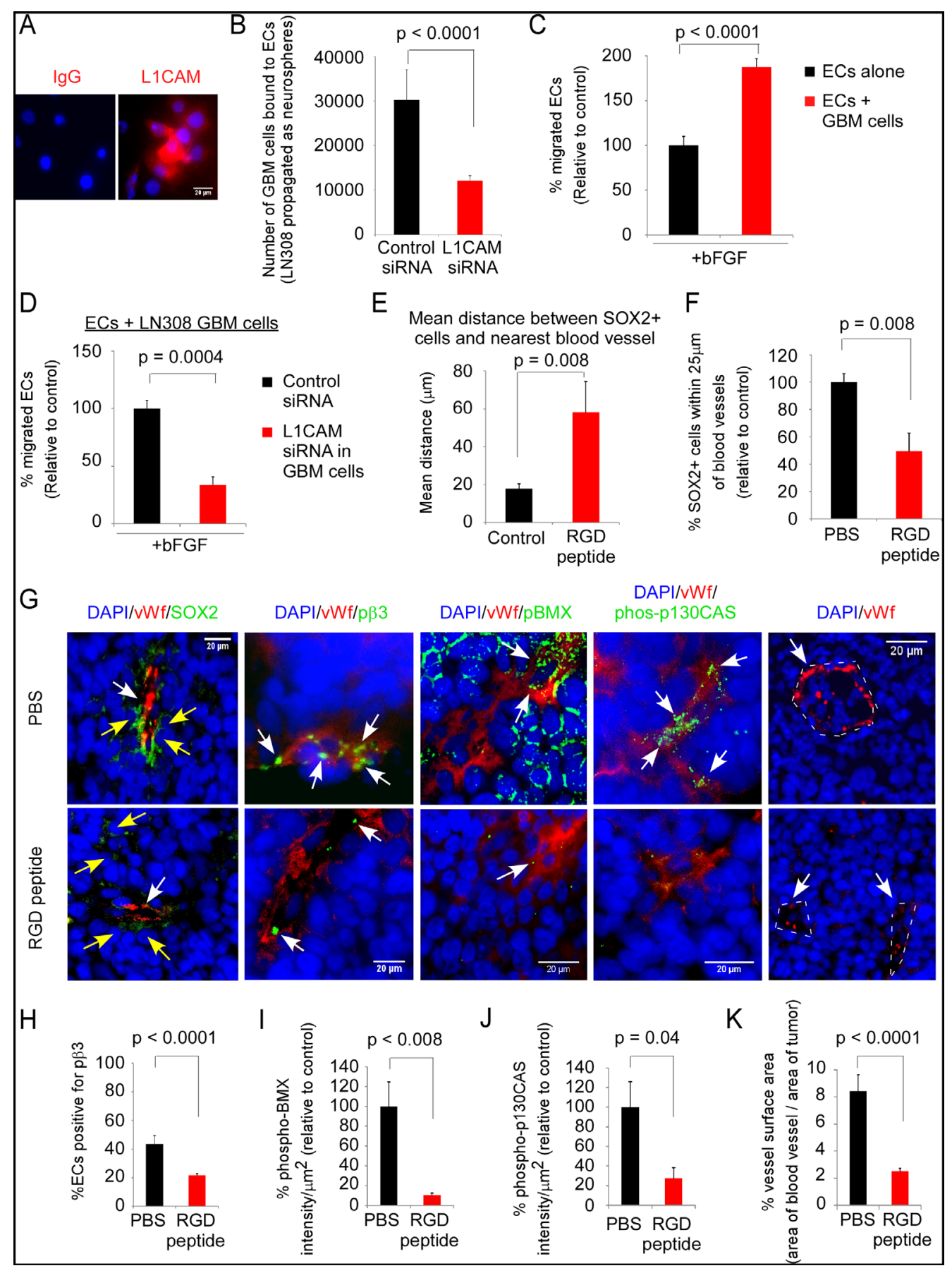

Figure 7: Administration of the RGD-peptide significantly reduces the proximity of Sox2-positive tumor cells to ECs, and BMX and p130CAS activation in ECs in an intracerebral xenograft model of GBM. A-D. LN-308 human GBM cells propagated in complete NBM in suspension were fluorescent-labeled for L1CAM (Alexa-594-red) (A); allowed to adhere to a monolayer of ECs after downregulation of L1CAM (B); mixed with ECs, plated on laminin-coated filters and allowed to migrate to bFGF as in Figure 5 (C), or L1CAM was downregulated and the migration assay repeated (D). E-K. LN-308 cells $(100,000)$ were injected into the nude mouse brain, tumor allowed to establish for 55 days, and cyclic-RGD-peptide $(90 \mathrm{mg} / \mathrm{kg}$ ) or PBS were administered for 5 days ( $\mathrm{n}=5$ mice/group), followed by euthanasia at $2 \mathrm{~h}$ post-treatment and brain harvest. Sections double-labeled for vWf (Alexa-594, red) and either Sox2, p 33 -(Y759), phospho-BMX, or phospho-p130CAS (Y234) (Alexa-488, green), and DAPI nuclear staining (G). The mean Sox2-positive tumor cell distance from vWf-positive ECs (E), percent Sox2-positive tumor cells within $25-\mu \mathrm{m}$ of a vWf-positive vessel (F), percent ECs positive for $\mathrm{p} \beta 3$ (H), intensity of phosphoBMX in tumor-associated ECs (I), intensity of phospho-p130CAS in tumor-associated ECs (J), and vessel surface area in the tumor (K) from RGD-peptide-treated mouse tumors relative to vehicle-treated control tumors. The intensity of phospho-BMX and phospho-p130CAS was calculated using FIJI (ImageJ) as in Figure 2 E\&2F for vWf-positive blood vessels, and traced along their outer edge for each field taken at 40X magnification. Signal intensity was normalized by dividing the sum of the mean gray level by the area of the ECs in each blood vessel. Statistics: B-F, two-sided exact Wilcoxon rank-sum tests; and H-K, linear mixed regression model. Data graphed as the mean \pm SEM. 
of ECs induced by the direct interaction with CSCs and the signals induced by the soluble factors present in CM/ $\mathrm{EC}+\mathrm{CSC}$. These differences included the requirement for BMX for cell-contact induced signaling of migration, as evidenced by the downregulation of BMX and the use of a BMX inhibitor. These differences occurred in the context of some signals that were induced in both ECs that interacted directly CSCs and by soluble factors present in $\mathrm{CM} / \mathrm{EC}+\mathrm{CSC}$. Such shared signaling may form the framework for the migratory behavior of the ECs whether or not they come into direct contact with the CSCs and will provide a basis for further investigation of, for example, the EC migratory polarity observed without CSCs, which most likely can be attributed to the chemotactic gradient of bFGF, and the induction of unpolarized migration in the 7-24 h time frame of ECs that did not come into contact with CSCs.

Our in vivo animal studies indicate that treatment of an established GBM xenograft tumor with cyclic-RGDpeptide significantly increased the mean distance of Sox2positive tumor cells from ECs as compared to controls. We also observed significant decreases in the percent of ECs with integrin $\alpha v \beta 3$ activation, in BMX activation and p130CAS phosphorylation in ECs, and in vessel surface area in tumors from RGD-peptide-treated mice. A clinical trial of the cyclic-RGD-peptide (Cilengitide) in combination with standard chemo-radiation for patients with newly diagnosed GBM showed improvement of survival in a subset of patients [47]. Our current data indicate previously unrecognized mechanisms of action that may affect therapeutic responsiveness.

Prior studies that have shown that integrin $\alpha v \beta 3$ cooperation with bFGF promotes angiogenesis [9, 48-50] utilized models that do not take into account the effects of direct contact with perivascular CSCs or tumor cells on integrin $\alpha v \beta 3$ signaling in the ECs. The current studies provide insights and also raise questions that are relevant to the ongoing development of strategies for utilization of targeted therapies, and most especially those directed to integrin $\alpha v \beta 3$, L1CAM and ERK. In terms of regulation of signaling, for example, integrin $\alpha v \beta 3$ cooperation with bFGF in confluent monolayers of ECs has been shown to be due to a complex formed between integrin $\alpha v \beta 3$, the tetraspanin CD9, and the junctional adhesion molecule-A (JAMA) that upon bFGF stimulation releases JAMA thereby regulating ERK activation and migration [51] but it is not known whether a similar complex is formed in the context of EC-CSC contact. Others have reported that cell surface expression of L1CAM is regulated by endocytosis, through a process that requires Numb, a negative regulator of Notch signaling [52]. In some cancers (e.g., lung and breast cancer) activated ERK signaling drives alternative splicing of Numb resulting in expression of the Numb-E9 isoform that can enhance Notch signaling [53]. Also, activation of Notch signaling by its ligand Delta-like 4 promotes angiogenesis in tumors
[54]. These data raise the intriguing question as to whether similar mechanisms affect cell surface L1CAM expression in GBM, and the intersection between Notch and ERK signaling and the cell interaction model that we propose in shaping tumor-associated angiogenesis. Although others have reported that, during metastasis, melanoma cells undergo transendothelial cell migration through a mechanism involving an interaction between integrin $\alpha v \beta 3$ on melanoma cells and L1CAM on ECs [55], it should be noted that GBM tumors rarely metastasize outside of the brain [2]. Finally, it is not known if the CSC-EC interaction also promotes survival and, if so, whether it does so through a mechanism akin to that observed on binding to an extracellular substrate $[56,57]$.

In summary, we have identified a previously unrecognized integrin $\alpha v \beta 3 / \mathrm{bFGF}$ initiated signaling event in the perivascular niche in GBM, involving EC contact with CSCs or tumor cells that requires BMX for activation of p130CAS and promotes chemotactic migration of ECs and thereby angiogenesis.

\section{MATERIALS AND METHODS}

\section{Cells}

Primary human normal brain ECs were purchased (Cell Systems, Kirkland, WA), cultured in EGM medium with growth factors (SingleQuots; Lonza, Basal, Switzerland), used in the first eight passages and von Willebrand factor (vWf) expression verified repeatedly, as described [30]. Primary human CSCs or NSTCs (08387) from four different GBM xenografts $(08387,3691,3832$, 4302) were isolated and propagated as neurospheres in complete neural basal medium (NBM) (Life Technologies, Waltham, MA) without FBS, as described [58]. Re-authenticated LN-308 cells were received from Dr. Nicolas de Tribolet (Lausanne, Switzerland). Re-authentication was performed by DNA profiling of 8 highly polymorphic regions of Short Tandem Repeats using Nonaplex PCR at the Leibniz Institute DSMZ German Collection of Microorganisms and Cell Cultures before use in these experiments. ECs were labeled with PKH26-red-fluorescent cell linker (Sigma, St. Louis, MO). Human astrocytes were purchased (Cell Systems) and cultured in DMEM with 10\% FBS. U-118 MG GBM cells expressing L1LE or vector control (K1879) have been described previously [28]. The U-118/L1LE and U-118/ K1879 vector control cell lines were authenticated to the HTB-15 (U-118 MG) human ATCC cell line by DNA profiling of 17 short tandem repeat (STR) loci plus the gender determining loci at the ATCC.

\section{Inhibitors and downregulation studies}

Peptides (Peptides International, Louisville, KY) and PP2 (EMD Millipore) were purchased. Cyclic- 
RGD-peptide (Cilengitide) used in the mouse model was provided by Merck (Darmstadt, Germany). The FAK inhibitor PF573228 was purchased from Santa Cruz, and the BMX-Inhibitor-1 was purchased from EMD Millipore. Both were used at a final concentration of $1 \mu \mathrm{M}$.

Small interfering ON-TARGETplus SMART pool RNA (siRNA) oligonucleotides were purchased (Dharmacon, Lafayette, CO). Pre-designed single target siRNA oligonucleotides for integrin $\beta 3$ were purchased from Sigma (SASI Hs01 00174222) and Life Technologies (s7582). Pre-designed single target siRNA oligonucleotides for L1CAM were purchased from Life Technologies (s8036, s8037, s8038). Pre-designed single target siRNA oligonucleotides for p130CAS were purchased from Life Technologies (s225161, s18373). Cells were transfected with oligonucleotides (HiPerfect, Qiagen, Hilden, Germany) and downregulation confirmed by immunoblotting $[30,59]$.

\section{Antibodies}

Antibodies were purchased: monoclonal antibodies, anti-integrin $\alpha v \beta 3$, anti-integrin $\beta 3(\mathrm{CD} 61)$, and antiintegrin $\alpha 5 \beta 1$ (Millipore, Billerica, MA), anti-human CD171 (L1CAM; BD Pharmingen, San Diego, CA), anti-integrin $\alpha v \beta 5$ (R\&D Systems, Minneapolis, MN), anti-actin, anti- $\beta$-tubulin, anti-phospho-ERK, and antiphospho-JNK (Santa Cruz, Dallas, TX), and anti-L1CAM UJ127 (GeneTex, Irvine, CA); rabbit antibodies, antiintegrin $\beta 3$ (Epitomics, Burlingame, CA), and antiphospho-FAK (Y397), anti-total FAK, anti-phosphoBMX/Etk (Y40), anti-total BMX/Etk, and anti-total p130CAS (E1L9H) (Cell Signaling, Beverly, MA). Rabbit affinity purified phospho-specific anti-p130CAS (Y234) was generated using the following peptide: -AQPEQDE[pY]DIPRHL, corresponding to residues 227 240 in human p130CAS, by 21st Century Biochemicals, Inc (Marlboro, MA) (SFigure 4).

\section{Immunofluorescence}

Cells were multi-labeled for immunofluorescence as described [30]. Confocal images were taken at $0.5 \mu \mathrm{m}$ steps (40X objective lens) using a Leica-TCS-SP5IIAOBS confocal microscope (NDD detector).

\section{Cell-cell adhesion}

Adhesion assay buffer: (140 mM NaCl, $5.4 \mathrm{mM}$ $\mathrm{KCl}$, $5.56 \mathrm{mM}$ D-glucose, $10 \mathrm{mM}$ Hepes, pH 7.4, 1mM $\mathrm{MgCl}_{2}, 100 \mathrm{uM} \mathrm{MnCl}_{2}, 1 \% \mathrm{BSA}$ ). Before cell seeding, the plate was blocked with 5\% BSA (30 min). ECs were seeded overnight on collagen type I (MP Biomedicals) and the EC monolayer was confluent prior to beginning the assay. CSCs remaining attached to ECs were calculated based on a CSC standard curve (SFigure 1A).

\section{Matrigel ${ }^{\circledR}$ EC network formation}

Cells were seeded onto polymerized Matrigel $^{\circledR}$ in complete NBM. Pictures (5X-magnification) from three independent assays were taken using a Zeiss A1 microscope. CM from CSCs was prepared by seeding CSCs on laminin in complete NBM (72 h).

\section{Motility assays}

For the 2D assay, cell culture inserts and the Chemotaxis and Migration Tool 2.0 (Ibidi, Madison, WI) were used. Inserts were coated with $20 \mu \mathrm{g} / \mathrm{ml}$ laminin (R\&D Systems). PKH26-red-fluorescent-ECs in EGM media were plated on one side of the insert, and GFPCSCs in complete NBM on the other side. Subsequently, the media was replaced with complete NBM, the insert removed, and live-imaging of cells into the gap initiated using a 10X objective lens and a motorized-stage (LeicaDMI6000-ImageEM/Orca-R2-ImageProPlus). Manual Tracking (Image J) was used to trace EC paths into the $500 \mu \mathrm{m}$ gap [60]. ECs trajectories were projected onto the XY plane and the average velocity calculated for individual and total trajectories [60].

For analysis of CSCs/ECs migrating into the wound gap, an automated algorithm was generated by ImageIQ (Cleveland, $\mathrm{OH}$ ) designed to batch process and analyze time-lapse, multi-channel stacks within ImageProPlus-7.0.

For the Transwell ${ }^{\circledR}$ assay, cells were seeded on the upper filter surface (Transwell chambers, 3- $\mu \mathrm{m}$ pore, Corning), allowed to migrate, cells on the upper surface removed, and cells on the lower filter surface washed, fixed [11], photographed and counted in 5-10 fields with a 20X objective (Leica-DFC425C-QImaging-Q15729QCapturePro).

\section{qRT-PCR}

RNA was harvested, reverse transcribed, and quantitative PCR performed using the Syber Green system; levels of mRNA were normalized to GAPDH, as described [30].

\section{Animal studies}

Animal experiments were carried out as described [61] with the approval of the Institutional Animal Care and Use Committee at the University Hospital Zurich (Zurich, Switzerland). LN-308 cells ( $10^{5}$ cells in $\left.2-\mu 1\right)$ were stereotactically injected into the striatum of 6-12 week-old anesthetized athymic CD1 nude mice (Charles Rivers Laboratories, Wilmington, MA). 


\section{Statistics}

All statistical analyses were performed/overseen by the Biostatistician (ASN). The statistical test used is stated in the figure legend; a $p$ value $<0.05$ was considered significant.

\section{ACKNOWLEDGMENTS}

We thank Dr. Kathy Hasenbach for assistance with animal studies, Sam Butler for assistance with biostatistics, and Dr. Fiona Hunter for critically reading the manuscript.

\section{CONFLICTS OF INTEREST}

M. Weller has received honoraria for participation in advisory boards and research support from Merck Serono. No potential conflicts of interest were disclosed by other authors.

\section{GRANT SUPPORT}

Supported by NIH-NCI CA175120 and NIH-NCI CA152883 to CLG.

\section{REFERENCES}

1. Ahluwalia MS, Gladson CL. Progress on antiangiogenic therapy for patients with malignant glioma. J Oncol 2010; 2010: 689018.

2. Onishi M, Ichikawa T, Kurozumi K, Date I. Angiogenesis and invasion in glioma. Brain Tumor Pathol 2011; 28:13-24.

3. Hardee ME, Zagzag D. Mechanisms of glioma-associated neovascularization. Am J Pathol 2012; 181:1126-41.

4. Folkins C, Shaked Y, Man S, Tang T, Lee CR, Zhu Z, Hoffman RM, Kerbel RS. Glioma tumor stem-like cells promote tumor angiogenesis and vasculogenesis via vascular endothelial growth factor and stromal-derived factor 1. Cancer Res 2009; 69:7243-51.

5. Bao S, Wu Q, Sathornsumetee S, Hao Y, Li Z, Hjelmeland AB, Shi Q, McLendon RE, Bigner DD, Rich JN. Stem cell-like glioma cells promote tumor angiogenesis through vascular endothelial growth factor. Cancer Res 2006; 66:7843-8.

6. De Bock K, Georgiadou M, Schoors S, Kuchnio A, Wong BW, Cantelmo AR, Quaegebeur A, Ghesquière B, Cauwenberghs S, Eelen G, Phng LK, Betz I, Tembuyser B, et al. Role of PFKFB3-driven glycolysis in vessel sprouting. Cell 2013; 154:651-663.

7. Ding Q, Stewart JEJr, Olman MA, Klobe MR, Gladson CL. The Pattern of Enhancement of Src Kinase Activity on Platelet-derived Growth Factor Stimulation of Glioblastoma Cells Is Affected by the Integrin Engaged. J Biol Chem 2003; 278:39882-39891.
8. Huttenlocher A, Horwitz AR. Integrins in cell migration. Cold Spring Harb Perspect Biol 2011; 3:a005074.

9. Cheresh DA, Stupack DG. Regulation of angiogenesis: apoptotic cues from the ECM. Oncogene 2008; 27:6285-98.

10. Guerrero MS, Parsons JT, Bouton AH. Cas and NEDD9 contribute to tumor progression through dynamic regulation of the cytoskeleton. Genes Cancer 2012; 3:371-381. doi: $10.1177 / 1947601912458585$.

11. Ding Q, Stewart JE Jr, Prince CW, Chang P-L, Trikha M, Han X, Grammer JR, Gladson CL. Promotion of Malignant Astrocytoma Cell Migration by Osteopontin Expressed in the Normal Brain: Differences in Integrin Signaling During Cell Adhesion to Osteopontin Versus Vitronectin. Cancer Res, 2002, 62:5336-5343.

12. Natarajan M, Stewart JE Jr, Golemis E, Pugacheva E, Alexandropoulos K, Grammer JR, Gladson CL. HEF1 is a Necessary and Specific Downstream Effector of FAK that Promotes the Migration of Glioblastoma Cells. Oncogene, 2006; 25:1721-1732.

13. Kiefel H, Bondong S, Hazin J, Ridinger J, Schirmer U, Riedle S, Altevogt P. L1CAM: a major driver for tumor cell invasion and motility. Cell Adh Migr 2012; 6:374-84.

14. Montgomery AM, Becker JC, Siu CH, Lemmon VP, Cheresh DA, Pancook JD, Zhao X, Reisfeld RA. Human neural cell adhesion molecule L1 and rat homologue NILE are ligands for integrin alpha v beta 3. J Cell Biol 1996; 132:475-85.

15. Chen MM, Lee CY, Leland HA, Lin GY, Montgomery AM, Silletti S. Inside-out regulation of L1 conformation, integrin binding, proteolysis, and concomitant cell migration. Mol Biol Cell 2010; 21:1671-85.

16. Gast D, Riedle S, Kiefel H, Muerkoster SS, Schafer H, Schafer MK, Altevogt P. The RGD integrin binding site in human L1-CAM is important for nuclear signaling. Exp Cell Res 2008; 314:2411-8.

17. Oleszewski M, Beer S, Katich S, Geiger C, Zeller Y, Rauch $\mathrm{U}$, Altevogt P. Integrin and neurocan binding to L1 involves distinct Ig domains. J Biol Chem 1999; 274:24602-10.

18. Anderson, HJ, Galileo DS. Small-molecule inhibitors of FGFR, integrins, and L1CAM selectively decrease L1CAMstimulated glioblastoma cell motility and proliferation. Cell Oncol 2016; Feb 16. [Epub ahead of print].

19. Calabrese C, Poppleton H, Kocak M, Hogg TL, Fuller C, Hamner B, Oh EY, Gaber MW, Finklestein D, Allen M, Frank A, Bayazitov IT, Zakharenko SS, et al. A perivascular niche for brain tumor stem cells. Cancer Cell 2007; 11:69-82.

20. Lathia JD, Gallagher J, Heddleston JM, Wang J, Eyler $\mathrm{CE}$, MacSwords J, Wu Q, Vasanji A, McLendon RE, Hjelmeland $\mathrm{AB}$, Rich JN. Integrin alpha 6 regulates glioblastoma stem cells. Cell Stem Cell 2010; 6:421-432.

21. Galan-Moya EM, Le Guelte A, Lima Fernandes E, Thirant C, Dwyer J, Bidere N, Couraud PO, Scott MG, Junier MP, Chneiweiss H, Gavard J. Secreted factors from brain 
endothelial cells maintain glioblastoma stem-like cell expansion through the mTOR pathway. EMBO Rep 2011; 12:470-6.

22. Charles N, Ozawa T, Squatrito M, Bleau A-M, Brennan CW, Hambardzumyan D, Holland EC. Perivascular nitric oxide activates notch signaling and promotes stem-like character in PDGF-induced glioma cells. Cell Stem Cell 2010; 6:doi:10.1016/j.stem.2010.01.001.

23. Lathia JD, Li M, Hall PE, Gallagher J, Hale JS, Wu Q, Venere M, Levy E, Rani MR, Huang P, Bae E, Selfridge J, Cheng L, et al. Laminin alpha-2 enables glioblastoma stem cell growth. Ann Neurol 2012; 2:766-778.

24. Lugassy C, Wadehra M, Li X, Corselli M, Akhavan D, Binder SW, Péault B, Cochran AJ, Mischel PS, Kleinman HK, Barnhill RL. Pilot study on "pericytic mimicry" and potential embryonic/stem cell properties of angiotropic melanoma cells interacting with the abluminal vascular surface. Cancer Microenviron 2013; 6:19-29.

25. Gladson CL. Expression of integrin alpha $\mathrm{v}$ beta 3 in small blood vessels of glioblastoma tumors. J Neuropathol Exp Neurol 1996; 55:1143-9.

26. Bao S, Wu Q, Li Z, Sathornsumetee S, Wang H, McLendon RE, Hjelmeland AB, Rich JN. Targeting cancer stem cells through L1CAM suppresses glioma growth. Cancer Res 2008; 68:6043-8.

27. Silletti S, Mei F, Sheppard D, Montgomery AM. Plasminsensitive dibasic sequences in the third fibronectin-like domain of L1-cell adhesion molecule (CAM) facilitate homomultimerization and concomitant integrin recruitment. J Cell Biol 2000; 149:1485-502.

28. Mohanan V, Temburni MK, Kappes JC, Galileo DS. L1CAM stimulates glioma cell motility and proliferation through the fibroblast growth factor receptor. Clin Exp Metastasis 2013; 30:507-520.

29. Fael Al-Mayhani TM, Ball SL, Zhao JW, Fawcett J, Ichimura K, Collins PV, Watts C. An efficient method for derivation and propagation of glioblastoma cell lines that conserves the molecular profile of their original tumours. J Neurosci Methods 2009; 76:192-9.

30. Huang P, Rani MR, Ahluwalia MS, Bae E, Prayson RA, Weil RJ, Nowacki AS, Hedayat H, Sloan AE, Lathia JD, Rich JN, Tipps R, Gladson CL. Endothelial expression of TNF receptor-1 generates a proapoptotic signal inhibited by integrin alpha6beta1 in glioblastoma. Cancer Res 2012; 72:1428-37.

31. Mahabeleshwar GH, Chen J, Feng W, Somanath PR, Razorenova OV, Byzova TV. Integrin affinity modulation in angiogenesis. Cell Cycle 2008; 7:335-47.

32. Somanath PR, Ciocea A, Byzova TV. Integrin and growth factor receptor alliance in angiogenesis. Cell Biochem Biophys 2009; 53:53-64.

33. Gangemi RM, Griffero F, Marubbi D, Perera M, Capra MC, Malatesta P, Ravetti GL, Zona GL, Daga A, Corte G. SOX2 silencing in glioblastoma tumor-initiating cells causes stop of proliferation and loss of tumorigenicity. Stem Cells 2009; 27:40-8.

34. Huang C, Jacobson K, Schaller MD. MAP kinases and cell migration. J Cell Science 2004; 117:4619-28.

35. Beadle C, Assanah MC, Monzo P, Vallee R, Rosenfeld SS, Canoll P. The role of myosin II in glioma invasion of the brain. Mol Biol Cell 2008; 19:3357-68.

36. Abassi YA, Rehn M, Ekman N, Alitalo K, Vuori K. p130CAS couples the tyrosine kinase Bmx/Etk with regulation of the actin cytoskeleton and cell migration. $\mathrm{J}$ Biol Chem 2003; 278:35636-35643.

37. Chatterjee S, Matsumura A, Schradermeier J, Gillespie GY. Human malignant glioma therapy using anti-alpha(v)beta(3) integrin agents. J Neurooncol 2000; 46:135-44.

38. Mikkelsen T, Brodie C, Finniss S, Berens ME, Rennert JL, Nelson K, Lemke N, Brown SL, Hahn D, Neuteboom B, Goodman SL. Radiation sensitization of glioblastoma by cilengitide has unanticipated schedule-dependency. Int J Cancer 2009; 124:2719-27.

39. He Z, Luo Y, Tang S, Rajantie I, Salven P, Heil M, Zhang R, Luo D, Li X, Chi H, Yu J, Carmeliet P, Schaper W et al. Critical function of Bmx/Etk in ischemia-mediated arteriogenesis and angiogenesis. J Clin Invest 2006; 116:2344-2355.

40. Holopainen T, Lopez-Alpuche V, Zheng W, Heljasvaara R, Jones D, He Y, Tvorogov D, D'Amico G, Wiener Z, Andersson LC, Pihlajaniemi T, Min W, Alitalo K. Deletion of the endothelial Bmx tyrosine kinase decreases tumor angiogenesis and growth. Cancer Res 2012; 72:3512-21.

41. Nikonova AS, Gaponova AV, Kudinov AE, Golemis EA. CAS proteins in health and disease. IUBMB Life 2014; 66:387-395.

42. Qiu Y, Kung H-J. Signaling network of the Btk family kinases. Oncogene 2000; 19:5651-5661.

43. Takesono A, Finkelstein LD, Schwartzberg PL. Beyond calcium: new signaling pathways for Tec family kinases. J Cell Science 2002; 115:3039-3048.

44. Chen R, Kim O, Li M, Xiong X, Guan J-L, Kung H-J, Chen H, Shimizu Y, Qiu Y. Regulation of the PH-domaincontaining tyrosine kinase Etk by focal adhesion kinase through the FERM domain. Nat Cell Biol 2001; 3:439-444.

45. Zhang R, Xu Y, Ekmans N, Wu Z, Wu J, Alitalo K, Min W. Etk/Bmx transactivates vascular endothelial growth factor 2 and recruits phosphatidylinositol 3-kinase to mediate the tumor necrosis factor-induced angiogenic pathway. J Biol Chem 2003; 278:51267-51276.

46. Chen, S, Jiang X, Gewinner CA, Asara JM, Simon NI, Cai C, Cantley LC, Balk SP. Tyrosine kinase BMX phosphorylates phosphotyrosine-primed motif mediating the activation of multiple receptor tyrosine kinases. Science Signal 2013; 6:doi: 10.1126/scisignal.2003936. 
47. Nabors LB, Fink KL, Mikkelsen T, Grujicic D, Tarnawski R, Nam do H, Mazurkiewicz M, Salacz M, Ashby L, Zagonel V, Depenni R, Perry JR, Hicking C, et al. Two cilengitide regimens in combination with standard treatment for pateints with newly diagnosed glioblastoma and unmethylated MGMT gene promoter:results of the openlabel, controlled, randomized phase II CORE study. Neuro Oncol 2015; 17:708-717.

48. Friedlander M, Brocks PC, Shaffer RW, Kincaid CM, Varner JA, Cheresh DA. Definition of two angiogenic pathways by distinct av integrins. Science 1995; 270:1500-1502.

49. Hood JD, Frausto R, Kiosses WB, Shwartz MA, Cheresh DA. Differential $\alpha v$ integrin-mediated Ras-ERK signaling during two pathways of angiogenesis. J Cell Biol 2003; 162:933-943.

50. Naik MU, Mousa SA, Parkos CA, Naik UP. Signaling through JAM- 1 and $\alpha \mathrm{v} \beta 3$ is required for the angiogenic action of the bFGF:dissociation of the JAM- 1 and $\alpha v \beta 3$ complex. Blood 2003; 102:2108-2114.

51. Peddibhotla SSD, Brinkmann BF, Kummer D, Tuncay H, Nakayama M, Adams RH, Gerke V, Ebnet K. Tetraspanin CD9 links junctional adhesion molecule-A to $\alpha v \beta 3$ integrin to mediate basic fibroblast growth factor-specific angiogenic signaling. Mol Biol Cell 2013; 24:933-944.

52. Nishimura T, Fukata Y, Kato K, Yamaguchi T, Matsuura Y, Kamiguchi H, Kaibuchi K. CRMP-2 regulates polarized Numb-mediated endocytosis for axon growth. Nat Cell Biol 2003; 5:819-826.

53. Rajendran D, Zhang Y, Berry DM, McGlade CJ. Regulation of Numb isoform expression by activated ERK signaling. Oncogene 2016; 1-12.
54. Dominguez M. Oncogenic programmes and Notch activity: an 'organized crime'? Sem Cell Develop Biol 2014; 28:78-85.

55. Voura EB, Ramjeesingh RA, Montgomery AM, Siu CH. Involvement of integrin alpha(v)beta(3) and cell adhesion molecule L1 in transendothelial migration of melanoma cells. Mol Biol Cell 2001; 12:2699-710.

56. Behera R, Kumar V, Lohite K, Karnik S, Kundu GC. Activation of JAK2/STAT3 signaling by osteopontin promotes tumor growth in human breast cancer cells. Carcinogenesis 2010; 31:192-200.

57. Rice J, Courter DL, Giachelli CM, Scatena M. Molecular mediators of alphavbeta3-induced endothelial cell survival. J Vasc Res 2006; 43:422-36.

58. Eyler $\mathrm{CE}, \mathrm{Wu} \mathrm{Q}$, Yan $\mathrm{K}$, MacSwords JM, ChandlerMilitello D, Misuraca KL, Lathia JD, Forrester MT, Lee J, Stamler JS, Goldman SA, Bredel M, McLendon RE, Sloan AE, Hjelmeland AB, Rich JN. Glioma stem cell proliferation and tumor growth are promoted by nitric oxide synthase-2. Cell 2011; 146:53-56.

59. Wang D, Olman MA, Stewart J, Jr., Tipps R, Huang P, Sanders PW, Toline E, Prayson RA, Lee J, Weil RJ, Palmer CA, Gillespie GY, Liu WM, et al. Downregulation of FIP200 induces apoptosis of glioblastoma cells and microvascular endothelial cells by enhancing Pyk2 activity. PLoS One 2011; 6:e19629.

60. Meijering E, Dzyubachyk O, Smal I. Methods for cell and particle tracking. Methods Enzymol 2012; 504:183-200.

61. Roth P, Silginer M, Goodman SL, Hasenbach K, Thies S, Maurer G, Schraml P, Tabatabai G, Moch H, Tritschler I, Weller M. Integrin control of the transforming growth factor-beta pathway in glioblastoma. Brain 2013; 136:564-76. 